extent in bone osteoclasts. In our patients, who had apathetic hyperthyroidism with low concentrations of serum magnesium and high ones of alkaline phosphatase which reverted to normal after three months' treatment, the interesting aspect is the possible role of hypomagnesaemia in producing this type of hyperthyroidism.

${ }^{1}$ Lahey, F H, Annals of Internal Medicine, 1932, 5, 1123.

2 Fairclough, P O, and Besser, G M, British Medical fournal, 1973, 1, 364.

${ }^{3}$ Lehninger, A L, Biochemistry, The Molecular Basis of Cell Structure and Function, 2nd edn, p 825. New York, Worth, 1975.

${ }^{4}$ Neguib, M A, Lancet, 1963, 1, 1405.

(Accepted 8 December 1977)

Westminster Hospital, London SW1

PETER MARKS, MB, MRCP, senior research registrar

HASHMAT ASHRAF, MB, FRCS, surgical registrar

\section{Association between HLA-BW40 and alcoholic liver disease with cirrhosis}

Some alcoholics seem to develop cirrhosis more readily than others, and the influence of genetic and environmental factors on individual susceptibility has been discussed. ${ }^{1}$ Autoimmune mechanisms have also been implicated, since an increased prevalence of autoantibodies and evidence of cell-mediated immunity to liver tissue have been reported in patients with cirrhosis, ${ }^{2-4}$ particularly in women. ${ }^{2}$

Bailey $e t \mathrm{al}^{4}$ performed HLA typing on their patients with alcoholic liver disease and found an increased prevalence of HLA-B8. This is a known trait in several autoimmune disorders and has also been shown in chronic active hepatitis. Scott $e t a l^{5}$, however, could find no association between any HLA antigen and chronic active hepatitis or alcoholic cirrhosis. We report here the results of HLA typing in patients with alcoholic liver disease.

\section{Patients, methods, and results}

Forty-one patients with alcoholic liver disease were studied. Twenty-five patients (aged 37-74 years (mean 58); 8 women, 17 men) had cirrhosis. All of these patients had undergone liver biopsy and the diagnosis was based on clinical, biochemical, and histological criteria. Nine of the 25 also had the histological features of alcoholic hepatitis. The other 16 patients (aged 39-75 years (mean 56); 3 women, 13 men) had no evidence of cirrhosis on liver biopsy: four had alcoholic hepatitis, and 12 had fatty liver disease. Another 16 patients with different liver diseases also underwent HLA typing. Four had chronic persistent hepatitis, three had hepatitis B, two had hepatitis A, and three had minimal biochemical evidence of hepatic disease of unknown

Prevalence of HLA antigens in three groups of patients. Results are numbers of subjects positive for each antigen

\begin{tabular}{|c|c|c|c|c|}
\hline \multirow[b]{2}{*}{ HLA } & \multicolumn{3}{|c|}{ Patients with: } & \multirow[b]{2}{*}{$\begin{array}{l}\text { Healthy } \\
\text { controls } \\
(n=153)\end{array}$} \\
\hline & $\begin{array}{l}\text { Alcoholic liver } \\
\text { disease and } \\
\text { cirrhosis } \\
(n=25)\end{array}$ & $\begin{array}{l}\text { Alcoholic liver } \\
\text { disease without } \\
\text { cirrhosis } \\
(n=16)\end{array}$ & $\begin{array}{c}\text { Other liver } \\
\text { disease } \\
(n=16)\end{array}$ & \\
\hline $\begin{array}{l}\text { A1 } \\
\text { A2 } \\
\text { A3 } \\
\text { A9 } \\
\text { A10 } \\
\text { A11 } \\
\text { A28 } \\
\text { B5 } \\
\text { B7 } \\
\text { B8 } \\
\text { B12 } \\
\text { B13 } \\
\text { B14 } \\
\text { BW15 } \\
\text { B17 } \\
\text { B21 } \\
\text { B27 } \\
\text { BW35 } \\
\text { BW37 } \\
\text { BW40 }\end{array}$ & $\begin{array}{r}8 \\
15 \\
5 \\
5 \\
3 \\
1 \\
0 \\
4 \\
5 \\
4(16 \%) \\
6 \\
4 \\
1 \\
3 \\
2 \\
1 \\
0 \\
3 \\
1 \\
13(52 \%)\end{array}$ & $\begin{array}{r}5 \\
12 \\
2 \\
2 \\
2 \\
3 \\
0 \\
0 \\
2 \\
4(25 \%) \\
6 \\
0 \\
1 \\
4 \\
0 \\
1 \\
5 \\
4 \\
0 \\
3(19 \%)\end{array}$ & $\begin{array}{l}2 \\
11 \\
3 \\
5 \\
1 \\
0 \\
1 \\
1 \\
4 \\
5(31 \%) \\
1 \\
0 \\
0 \\
3 \\
1 \\
1 \\
5 \\
2 \\
0 \\
3(19 \%)\end{array}$ & $\begin{array}{l}40 \\
80 \\
36 \\
37 \\
13 \\
15 \\
8(+1 ?)^{*} \\
9 \\
41 \\
31(20 \%) \\
58 \\
3 \\
2 \\
30 \\
8 \\
4 \\
15 \\
23 \\
2 \\
28(18 \%)\end{array}$ \\
\hline
\end{tabular}

*Anti-HLA-A28 cross-reacted with HLA-A2. One of the controls might therefore have been A2 homozygous, A2, A "blank," or A2, A28. origin. Four patients were classified as having non-alcoholic cirrhosis. HLA typing was performed by recommended microcytotoxic techniques. Fiftyfour typing sera were used, typing for 20 antigens. Three anti-HLA-BW 40 sera were used. All patients were typed blind. The control samples were from blood donors in Oslo. Controls and patients were typed within the same period using the same set of typing sera. $\chi^{2}$ values were calculated by two-by-two tables for each comparison separately.

The table shows all the antigens typed for, and the number of subjects positive for each. When computing the $\chi^{2}$ value for each comparison (60 in all) we found only one significant deviation from the normal distribution. Thirteen of the 25 patients $(52 \%)$ with alcoholic liver disease and cirrhosis were HLA-BW40 positive compared with 28 of the $153(18 \%)$ controls $\left(\chi^{2}=13.77,11.93\right.$ with Yates's correction; $\mathrm{P}<0.001$; when multiplied with the number of antigens tested for $(20), P<0.02)$. The prevalence of HLABW40 was not increased in the two other groups of patients, and the prevalence in the control group was the same as that in the Norwegian population. The prevalence of HLA-B8 did not differ significantly from normal in any group. Bailey et $a l^{4}$ noted an absence of HLA-A28 in both types of alcoholic liver disease, which we also found, but our groups were too small to yield statistically significant results.

\section{Comment}

Many associations have been shown between HLA antigens and different diseases-mostly chronic diseases of uncertain cause and sometimes with immunological manifestations. Even if excessive consumption of alcohol is the main agent in the development of alcoholic cirrhosis, its cause is still uncertain, since we do not know why only some heavy drinkers develop cirrhosis. The association with HLA-BW40 may support the idea that individual susceptibility to the development of alcoholic cirrhosis is genetically determined.

We know of no previous reports of an association between liver disease and HLA-BW40. Scott et al did not find an increased prevalence of HLA-BW40 among 18 patients with alcoholic cirrhosis, ${ }^{5}$ and Bailey et $a l^{4}$ did not type for HLA-BW40. We were not able to confirm the findings of Bailey et $a^{4}$ of an excess of HLA-B8 among patients with alcoholic liver disease, which suggested that alcoholic disease might belong to the group of autoimmune diseases, in which several associations with HLA-B8 have been shown.

${ }^{1}$ Klatskin, G, Gastroenterology, 1961, 41, 443.

${ }^{2}$ Krasner, N, et al, British Medical fournal, 1977, 1, 1497.

3 Mihas, A A, Bull, D M, and Davidson, C S, Lancet, 1975, 1, 951

${ }^{4}$ Bailey, R J, et al, British Medical fournal, 1976, 2, 727.

5 Scott, B B, et al, Gastroenterology, 1977, 72, 122.

(Accepted 24 November 1977)

Krohgst $\phi$ tten Department of Oslo City Hospital, Oslo 1, Norway

H BELL, MD, university lecturer

Department of Immunology, National Blood Group Reference Laboratory and Tissue Typing Unit, National Institute of Public Health, Postuttak Oslo 1, Norway

R NORDHAGEN, MD, deputy director

\section{Intracellular potassium after magnesium infusion}

Potassium loss in the urine is a well-known side effect of treatment with most diuretics, and usually potassium supplements are provided to avoid this. During the last few years interest has focused on the increased renal excretion of magnesium resulting from the use of most diuretics. ${ }^{1} \mathrm{~A}$ sustained increase in magnesium excretion may lead to a cellular magnesium deficiency, which by an insufficient activation of $\mathrm{Na}-\mathrm{K}-\mathrm{ATP}$-ase may result in the inability of the cell to maintain the high intracellular potassium concentration. Thus the cell fails to attract potassium despite an abundant supply, as shown also in animal studies. ${ }^{2}$ As the resting membrane potential is mainly a function of the logarithmic ratio between the intracellular and extracellular potassium, a change in only one of these factors results in a change in membrane potential: thus a decrease in intracellular potassium will lead to a less negative potential. In this way the resting membrane potential approaches the threshold potential and the cell becomes more excitable. 


\section{Patients, methods, and results}

We studied the frequency and type of ventricular extrasystoles as well as the intracellular and extracellular concentrations of sodium, potassium, and magnesium in 50 hypokalaemic patients taking long-term diuretic treatment before and after correction of the serum potassium concentration. The arrhythmias were recorded on a three-hour ECG tape. In 16 patients, eight of whom were hypokalaemic at the start of the study, we also investigated the frequency and type of ventricular extrasystoles, and the intracellular and extracellular electrolyte concentrations after an infusion of $30 \mathrm{mmol}$ magnesium sulphate.

Percutaneous muscle biopsy specimens were obtained from the lateral portion of the quadriceps femoris with a needle biopsy technique. After repeated weighing, drying, and fat extraction, the dried muscle tissue was wet ashed in $1 \mathrm{~N}$ nitric acid. The magnesium, potassium, sodium, and chloride contents were then determined by atomic absorption spectrophotometry, chloride after precipitation with silver nitrate. The intracellular and extracellular spaces were calculated by the chloride method, given that chloride is freely diffusible across the cell membrane and distributed according to Nernst's equation. ${ }^{3}$ Paired $t$ tests were used to compare the serum and muscle electrolyte concentrations as well as the frequency of ventricular extrasystoles before and after correction of the serum potassium concentration and before and after the magnesium infusion.

Mean extracellular and intracellular potassium before and after magnesium infusion

\begin{tabular}{|c|c|c|c|c|}
\hline & & $\underset{\substack{\text { potassium } \\
(\mathrm{mmol} / 1)}}{\text { Serum }}$ & $\begin{array}{c}\text { Muscle } \\
\text { potassium } \\
(\mathrm{mmol} / 100 \mathrm{~g} \mathrm{FFDS})\end{array}$ & $\begin{array}{c}\text { Intracellular } \\
\text { potassium } \\
(\mathrm{mmol} / \mathrm{kg} \text { water })\end{array}$ \\
\hline $\begin{array}{l}\text { Before } \\
\text { After } \\
\text { P }\end{array}$ & $\begin{array}{l}\cdots \\
\cdots\end{array}$ & $\begin{array}{l}4 \cdot 0 \\
3 \cdot 8 \\
\text { NS }\end{array}$ & $\begin{array}{l}39 \cdot 2 \\
40 \cdot 6 \\
\text { NS }\end{array}$ & $\begin{array}{l}153 \\
170 \\
<0.01\end{array}$ \\
\hline
\end{tabular}

Conversion: SI to traditional units-Potassium: $1 \mathrm{mmol}=1 \mathrm{mEq}$.

The preliminary results showed that there was no increase in the intracellular potassium concentration or the muscle potassium content after correction of the serum potassium concentration despite a significant increase in this. Nor was there any change in the frequency or type of ventricular extrasystoles after correction of the serum potassium concentration. After the magnesium infusions, however, the intracellular potassium concentration significantly increased, from a mean value of 153 to a mean value of 170 $\mathrm{mmol}(\mathrm{mEq}) \mathrm{kg}$ intracellular water $(\mathrm{P}<0.01)$. There was also an increase, although not significant, in the muscle potassium content (see table). All patients had also a lower frequency of ventricular extrasystoles after the magnesium infusions $(\mathrm{P}<0 \cdot 05)$.

\section{Discussion}

Our preliminary results imply that giving increased potassium supplements to patients taking long-term diuretic treatment does not necessarily augment the cellular uptake of potassium. This may be explained by a concomitant cellular magnesium deficiency with an insufficient activation of Na-K-ATP-ase. This theory is further supported by the increase in cellular potassium concentration obtained after magnesium infusion. This has been shown in studies of magnesium depletion in man $^{4}$ and in animal experiments. ${ }^{2}$

We believe that the urinary losses of magnesium after long-term treatment with most diuretics are of great importance and may impede the cellular accumulation of potassium and thus lead to increased cardiac excitability. Could this be the explanation for the increased frequency of ventricular extrasystoles found in patients treated with diuretics.5 Completion of these studies and further studies are in progress.

${ }^{1}$ Hänze, S, and Seyberth, H, Klinische Wochenschrift, 1967, 45, 313. 2 Whang, R, and Welt, R G, Fournal of Clinical Investigation, 1963, 42, 305.

${ }^{3}$ Graham, J A, Lamb, J F, and Linton, A L, Lancet, 1967, 2, 1172.

${ }^{4}$ Shils, M E, Medicine, 1969, 48, 61.

${ }^{5}$ Rehnqvist, N, European fournal of Cardiology, 1976, 4, 63.

(Accepted 8 December 1977)

Medical clinic, Serafimerlasarettet, Box 12700, 11283 Stockholm, Sweden

THOMAS DYCKNER, MD, assistant physician

Medical clinic, University Hospital, S-901 87 Umeå, Sweden $P$ O WESTER, MD, professor of medicine
HLA and DRW antigens in insulin-dependent diabetes

The existence of an association between certain diseases and the HLA system has stimulated considerable interest. In insulin-dependent diabetes (IDD) associations with HLA-A, B, or C antigens have been shown. ${ }^{1}$ In contrast, no correlation has been found with insulinindependent diabetes. B lymphocytes have been shown to possess antigens that are distinct from HLA-A, B, and C antigens. ${ }^{2}$ Antisera that react with $B$ lymphocytes but not with $T$ lymphocytes have been grouped into antigenic specificities, now called DRW. ${ }^{3}$ This study aimed to examine whether a relationship also exists between HLADRW specificities and IDD, taking into consideration certain complications such as retinopathy and neuropathy.

\section{Patients, methods, and results}

A total of 123 insulin-dependent diabetics were studied and compared with 176 normal controls. All patients were Caucasian and unrelated. The group comprised 56 women and 67 men (mean age 25 ). With the standard NIHTerasaki microlymphocytotoxicity test 17 HLA-A, 18 HLA-B, and 6 HLA-C were defined. To detect DRW antigens, the internationally accepted microcytotoxicity test was used. ${ }^{3}$ A total of 180 sera selected by the Seventh International Histocompatibility Workshop and 60 local sera defining accurately seven DRW specificities were used. Differences in HLA antigen frequencies between patients and controls were calculated by $\chi^{2}$ analysis.

The table shows the main differences of the distribution of HLA-A, B, C, and DRW antigens. Previous findings of an increased frequency of B8 and $\mathrm{B} 18$ and of a decreased frequency of B7 were confirmed. Furthermore, the antigens B8 and B 18 seem to have a cumulative effect to increase susceptibility to IDD $(R R=5 \cdot 25)$. In addition, we found important differences in the frequencies of $\mathrm{A} 11, \mathrm{~B} 5$, and $\mathrm{BW} 35$. Although these differences are no longer significant if the ordinary $\mathrm{P}$ values are corrected by the number of comparisons made, they agree with the data compiled by the HLA and Disease Registry. ${ }^{1}$ The most significant associations are with DRW antigens and particularly with DRW3. No noticeable differences in the distribution of HLA antigens were observed for patients with or without neuropathy. Some $39(32 \%)$ patients had retinopathy, of which 31 were benign and eight malignant (proliferative retinopathy). In the eight patients with malignant retinopathy, six had the antigen $B 8$ and four the antigen DRW3.

$H L A-A, B$, and $D R W$ antigen frequencies in IDD which show notable differences from control population

\begin{tabular}{|c|c|c|c|c|}
\hline Antigen & $\begin{array}{c}\text { Patients }\left({ }^{\prime}\right) \\
(\mathrm{n}=123)\end{array}$ & $\begin{array}{c}\text { Controls }(\%) \\
(n=176)\end{array}$ & $P$ value & $\mathrm{RR}$ \\
\hline $\begin{array}{l}\text { A11 } \\
\text { B5 } \\
\text { B7 } \\
\text { BW35 } \\
\text { B8 } \\
\text { B18 }\end{array}$ & $\begin{array}{c}8(6.5) \\
6(4.9) \\
16(13.0) \\
10(8.1) \\
46(37.4) \\
22(17.9)\end{array}$ & $\begin{array}{l}30(17 \cdot 1) \\
28(15 \cdot 9) \\
39(22 \cdot 2) \\
41(23 \cdot 3) \\
30(17 \cdot 1) \\
17(9 \cdot 7)\end{array}$ & $\begin{array}{l}<0.01 \\
<0.01 \\
<0.05 \\
<0.005 \\
<0.0005 \\
<0.05\end{array}$ & $\begin{array}{l}0 \cdot 34 \\
0 \cdot 27 \\
0.53 \\
0 \cdot 29 \\
2.91 \\
2.04\end{array}$ \\
\hline $\begin{array}{l}\text { DRW2 } \\
\text { DRW3 }\end{array}$ & $\begin{array}{c}9(7 \cdot 3) \\
73(59 \cdot 4)\end{array}$ & $\begin{array}{l}35 / 160(21 \cdot 9) \\
22 / 160(13 \cdot 8)\end{array}$ & $\begin{array}{l}<0.001 \\
<0.00025\end{array}$ & $\begin{array}{l}0 \cdot 25 \\
9 \cdot 16\end{array}$ \\
\hline
\end{tabular}

\section{Discussion}

The data of Thomsen, ${ }^{4}$ derived from using the mixed lymphocyte culture (MLC), suggest that the IDD susceptibility gene is probably closer to the $\mathrm{D}$ locus than the $\mathrm{B}$ locus of the HLA region. It appears likely that the B-lymphocyte antigens (DRW) are coded for by a locus identical or closely linked to the HLA-D locus as defined by the MLC. Our data using a serological approach indicate a strong association of the antigen DRW3 with IDD. The fact that the RR value of DRW3 (9.2) is much higher than that of B8 (2.9) suggests that the former is more strongly associated with IDD, and that the increase of B8 is secondary to that of DRW3 due to the well-established linkage disequilibrium between the two antigens. DRW 2 could be a protection marker and the decrease of B7 is also secondary to that of DRW2 due to linkage disequilibrium. In contrast to the results obtained by Thomsen with the MLC technique, ${ }^{4}$ we did not find an increase in DRW4, but this agrees with the lack of increased frequency of B15 and CW3 with which DRW4 is in linkage disequilibrium. In our study no firm relation between certain HLA antigens and neuropathy or retinopathy seemed to exist, except perhaps for an increase of B8 in malignant retinopathy.

The precise genetic basis of IDD is still controversial. Nevertheless, the results of our study suggests that a marker of the disease (HLA- 